\title{
Desafios no gerenciamento de resíduos em construção de pequeno porte
}

\author{
Lilyanne Rocha Garcez ${ }^{1}$ \\ Hosana Emília Sarmento Costa Leite ${ }^{2}$ \\ Juliana da Silva Araújo ${ }^{3}$ \\ Brenda de Souza Monteiro França ${ }^{4}$
}

\begin{abstract}
RESUMO
A indústria da construção civil é reconhecida como segmento de relevância para o desenvolvimento econômico e social, também considerada como setor que demanda uma expressiva quantidade de recursos naturais e gera um elevado volume de resíduos durante o processo construtivo. $\mathrm{O}$ gerenciamento dos Resíduos da Construção Civil é um desafio atual e a implantação de medidas que visem a redução ou a reciclagem desses resíduos pode contribuir para melhorias durante o processo construtivo. Assim, este trabalho tem como objetivo apresentar algumas práticas sustentáveis que podem ser adotadas por pequenos empreendimentos da construção civil, elencando possíveis soluções para os resíduos mais volumosos gerados em um canteiro de obras. Para apresentar as informações técnicas pertinentes foram analisadas três construtoras localizadas na mesorregião da Borborema, estado da Paraíba, que atuam com empreendimentos de pequeno porte na construção de casas populares. Com base na experiência observada, vale destacar que, para o desenvolvimento de ações sustentáveis, há a necessidade de se elaborar estratégias desde a fase de projeto e implementar uma cultura organizacional e educativa que envolva a execução de tais estratégias.
\end{abstract}

Palavras-chave: Resíduos Sólidos. Construção Civil. Pequenos Construtores. Canteiro de Obras.

\footnotetext{
${ }^{1}$ Graduada em Engenharia Civil pela Universidade Federal do Amazonas - UFAM. Mestra em Engenharia Civil pela Universidade Federal de Campina Grande - UFCG e Doutoranda em Ciência e Tecnologia de Materiais na Universidade Estadual Paulista - UNESP. É professora do Departamento de Engenharia Civil da Universidade Federal do Amazonas - UFAM, AM, Brasil. E-mail: lilyannegarcez@ gmail.com.

${ }^{2}$ Graduada em Engenharia Civil pela Universidade Federal da Paraíba - UFPB. Mestra em Engenharia Civil e Ambiental pela Universidade Federal de Campina Grande - UFCG e Doutoranda em Engenharia Civil na Universidade Federal de Pernambuco - UFPE. É professora do Instituto Federal de Pernambuco - IFPE, PE, Brasil. E-mail: hosanaemilia@ hotmail.com.

${ }^{3}$ Graduada em Engenharia Civil pelo Instituto Federal da Paraíba - IFPB, PB, Brasil.

${ }^{4}$ Graduada em Engenharia Civil pela Universidade Federal do Amazonas - UFAM, AM, Brasil. E-mail: bsmfranca@hotmail.com.
} 


\title{
Challenges in waste management in small construction
}

\begin{abstract}
The civil construction industry is recognized as a segment of relevance to the economic and social development of society, also considered a sector that demands an expressive amount of natural resources that generate a high volume of waste during the construction process. The management of Construction Waste is a current challenge and the implementation of measures aimed at reducing or recycling this waste can contribute to improvements during the construction process. Thus, this work aims to present some sustainable practices that can be adopted by small construction companies, listing possible solutions for the bulkier waste generated at a construction site. To present the pertinent technical information, three construction companies located in the mesoregion of Borborema, State of Paraiba, were analyzed, who work with a small enterprise in the construction of popular houses. Based on the observed experience, it is worth mentioning that for the development of sustainable actions there is a need to develop strategies from the design stage and to implement an organizational and educational culture that involves the execution of such strategies.
\end{abstract}

Keywords: Solid Waste. Construction. Small Builders. Construction Site.

Artigo recebido em: 29/04/2020

Aceito em: 27/07/2020 


\section{INTRODUÇÃO}

À medida que cresce a preocupação com o meio ambiente, vislumbra-se a necessidade de minimizar os impactos causados pela construção civil, não apenas os ocasionados pela exploração de matérias-primas, mas os oriundos de resíduos sólidos gerados por processos construtivos. De forma geral, os Resíduos Sólidos da Construção Civil e de Demolição (RCD) são vistos como resíduos de baixa periculosidade, porém o impacto no meio ambiente torna-se grande devido ao volume gerado durante a construção.

Alguns estudos evidenciam que a adoção de padrões de produção, consumos sustentáveis e o gerenciamento adequado dos resíduos sólidos podem reduzir significativamente os impactos causados (JACOBI, BESEN, 2011).

No Brasil, as políticas públicas voltadas ao gerenciamento de RCD buscam impulsionar as empresas geradoras de resíduos a tomarem uma nova postura gerencial e implementar medidas que visem a redução da quantidade de resíduos produzidos. Estas medidas, via de regra, ainda são consideradas como não usuais ou são até mesmo desconhecidas no setor da construção.

Para Fernandes (2017) aos poucos a situação começa a mudar nas municipalidades brasileiras, com prefeituras buscando desenvolver e implantar planos de gerenciamento de RCD em conformidade com as diretrizes da legislação e as normas vigentes. Entretanto, ainda são inúmeros os problemas decorrentes da falta de conhecimento e de um efetivo planejamento pelos responsáveis e executores de empreendimentos para uma eficaz gestão dos RCD.

Reitera-se também que a disposição irregular desses resíduos pode gerar problemas de ordem estética, ambiental e de saúde pública, pois, além dos resíduos volumosos, há presença de material orgânico, produtos químicos, tóxicos e embalagens diversas que podem acumular água e favorecer a proliferação de insetos e outros vetores de doenças, representando um grave problema de saúde e, muitas vezes, sobrecarregando os sistemas de limpeza pública (KLEIN, GONÇALVES DIAS, 2017).

Com base nesse contexto, torna-se necessária a criação de medidas para que os impactos ambientais provenientes da construção civil sejam minimizados, haja vista a quantidade de resíduos gerados. Salienta-se que alguns aspectos são de extrema relevância, como a classificação e a caracterização dos resíduos, para que se empregue técnicas aplicadas ao desenvolvimento sustentável durante os processos construtivos. 
Dessa forma, este trabalho tem como objetivo apresentar algumas práticas sustentáveis que podem ser adotadas por pequenos empreendimentos da construção civil, elencando possíveis soluções para os resíduos gerados no canteiro de obras.

\section{MATERIAIS E MÉTODOS}

Esta pesquisa consiste em um estudo exploratório que possibilitará a apresentação de alternativas para o reaproveitamento de resíduos gerados na construção civil, por meio de levantamento bibliográfico, e viabilizado a partir da realização de um levantamento de campo com profissionais da área e das atuações quanto ao gerenciamento dos resíduos em canteiros de obras.

A avaliação realizada teve como área de referência a construção de residências populares em alvenaria convencional e concreto armado, sendo visitados três canteiros de obras de construtoras de pequeno porte localizadas na mesorregião Borborema, microrregião Cariri, do estado da Paraíba. Para efetivação do estudo, analisou-se, junto aos engenheiros responsáveis, os impactos ambientais do empreendimento, as práticas de compatibilização e racionalização de projeto, a redução dos resíduos gerados, a prática de coleta seletiva e as políticas de reciclagem e de reutilização dos empreendimentos.

As visitas in loco e as conversas com os construtores tiveram por finalidade mapear as práticas gerenciais e administrativas, bem como as estratégias de produção que visam a redução do volume e a destinação de resíduos gerados, desde a concepção do projeto, passando pelas fases de construção, reforma, reparo e manutenção.

O estudo também envolveu pesquisa em artigos científicos que contribuíram com modelos de organização e possíveis soluções de reaproveitamento e reciclagem dos resíduos gerados durante a construção de residências populares.

\section{RESULTADOS E DISCUSSÃO}

\subsection{Concepção e execução nas construções de pequeno porte}

Para um melhor desenvolvimento das alternativas quanto às práticas sustentáveis na construção, serão inicialmente apresentados os resultados obtidos por meio de visitas realizadas às três construtoras que atuam em empreendimentos de pequeno porte na 
construção de casas populares. O Quadro 1 descreve os resíduos gerados durante as principais etapas da obra, considerando o processo construtivo em alvenaria convencional e concreto armado nos três empreendimentos analisados.

Quadro 1: Possíveis resíduos gerados com base no cronograma da obra

\begin{tabular}{|l|l|}
\hline \multicolumn{1}{|c|}{ ETAPAS DA OBRA } & \multicolumn{1}{c|}{ POSSÍVEIS RESÍDUOS GERADOS } \\
\hline $\begin{array}{l}\text { Instalação de canteiro e serviços } \\
\text { preliminares }\end{array}$ & $\begin{array}{l}\text { Solos com vegetação, peças de madeira e plásticos } \\
\text { oriundos da instalação do canteiro de obras }\end{array}$ \\
\hline Atividades administrativas & Papel e resíduo orgânico \\
\hline Escavação e terraplenagem & Solo \\
\hline Fundações e infraestrutura & Madeira das formas, aço e materiais cimentícios \\
\hline Superestrutura (pilares e vigas) & Areia, materiais cimentícios e derivados \\
\hline Escoramentos & Madeira \\
\hline Alvenarias e revestimentos & Materiais cerâmicos e materiais contaminantes \\
\hline Impermeabilizações & Materiais contaminantes \\
\hline Instalações elétricas e hidráulicas & Plásticos e metais \\
\hline Coberturas & Materiais cerâmicos e madeira da estrutura \\
\hline Esquadrias, serralheria e vidraçaria & Madeira, metais e vidros \\
\hline Paisagismo e recreação & Solo e gramas \\
\hline Mobiliário & Madeira e plásticos das embalagens \\
\hline $\begin{array}{l}\text { Limpeza da obra e desmobilização do } \\
\text { canteiro }\end{array}$ & $\begin{array}{l}\text { A depender da organização e coleta seletiva durante a } \\
\text { obra }\end{array}$ \\
\hline
\end{tabular}

Fonte: Autoria própria.

As construtoras visitadas apresentaram limitações quanto a práticas de compatibilização e racionalização de projeto, pois, comumente, não se efetua um estudo prévio de impactos ambientais causados pelos resíduos sólidos apresentados no Quadro 1, bem como não se possui um planejamento para a destinação adequada desses resíduos gerados durante a construção.

No que se refere ao cumprimento do licenciamento ambiental exigido pela legislação e pelo código de obras municipais, há uma realidade singular em casos de irregularidades, segundo a qual a adequação e a multa não são cobradas dos construtores devido à falta de fiscalização, cuja responsabilidade é dos órgãos públicos locais. 
Ainda foi possível observar que os projetos existentes nas obras se limitam ao esboço da planta baixa da edificação, que é deixado no canteiro de obras e destinado aos trabalhadores, como base para a elaboração dos serviços.

Quanto às soluções ambientais prévias, durante a concepção do projeto, as construtoras afirmaram não elaborar nenhum estudo, porém, enfatizaram que os trabalhadores são orientados a executar seus serviços de forma racional para evitar perdas e desperdícios de materiais. Essa postura é tomada visando a redução dos custos de produção e da quantidade de resíduos a serem enviados à destinação final. Assim, se consegue evitar a ocorrência de perdas incorporadas à edificação ou de retrabalhos que eventualmente podem acontecer.

Além disso, as três construtoras visitadas não efetuam a prática da coleta seletiva com base nos cumprimentos do Conselho Nacional do Meio Ambiente - CONAMA, que estabelece diretrizes por meio das Resoluções $N^{\circ} 275$ (CONAMA, 2001), $\mathrm{N}^{\circ} 307$ (CONAMA, 2002) e $\mathrm{N}^{\mathrm{o}} 448$ (CONAMA, 2012). Esse descumprimento dificulta os mecanismos de reaproveitamento de materiais no canteiro de obras ou de seu envio ao processo de reciclagem.

Na prática, os resíduos gerados são armazenados em contêineres próximos ao canteiro de obra para serem recolhidos pelo serviço de limpeza urbana municipal. Apesar da Resolução Nº 448 (CONAMA, 2012) regulamentar que os Resíduos da Construção Civil não podem ser dispostos junto com os resíduos urbanos, destaca-se que na localidade não existem aterros sanitários, privados ou públicos, destinados a resíduos da Indústria da Construção. Assim, os resíduos gerados nos canteiros de obra são depositados no aterro controlado do município, em comum acordo com a prefeitura local.

Salienta-se que a utilização dos recursos naturais de forma sustentável é possível e viável, principalmente quando há um planejamento prévio e desde que este seja um dos objetivos de todos os envolvidos no processo da construção. Ao se aplicar práticas sustentáveis, tem-se menor pressão do setor sobre os recursos naturais, além de benefícios como a redução de custos de produção e operacionais. Cabe ao empreendedor selecionar as melhores técnicas que estejam ao seu alcance de acordo com sua realidade (ROQUE, PIERRI, 2018).

Para Bamgbade et al. (2018), existe uma relação significativa entre o potencial econômico da construtora/empreendimento e o meio ambiente, em que os melhores resultados de práticas sustentáveis estão nos processos construtivos que envolvem cultura 
organizacional, design flexível, qualidade e diversidade do produto, aspectos que são comumente observados em empresas de grande porte.

\subsection{Materiais reutilizáveis e recicláveis na construção civil}

A construção civil produz resíduos durante o processo de construção ou de demolição que podem ser reaproveitados na própria obra, reutilizados em outros empreendimentos ou enviados à reciclagem. O Quadro 2 relaciona os tipos de materiais, comumente encontrados nas obras de pequeno porte, tendo como base a classificação da Resolução $N^{\circ} 307$ (CONAMA, 2002), reiterando que resíduos das classes C e D não são reaproveitados.

Quadro 2: Relação dos materiais recicláveis quanto à origem

\begin{tabular}{|c|c|c|}
\hline \multicolumn{2}{|c|}{ MATERIAIS } & ORIGEM \\
\hline \multirow{4}{*}{ CLASSE A } & Cerâmicas & \multirow{3}{*}{ Demolições e restos de obra } \\
\hline & Argamassa & \\
\hline & Concreto & \\
\hline & Solos & Escavações e serviços de terraplenagem \\
\hline \multirow{7}{*}{ CLASSE B } & Plástico & Embalagens de materiais, forros, PVC de instalações \\
\hline & Papel / Papelão & Embalagens de materiais e documentos \\
\hline & Metais & $\begin{array}{l}\text { Perfis metálicos, tubos de ferro, aço, esquadrias de alumínio, } \\
\text { grades de ferro e fios de cobre }\end{array}$ \\
\hline & Vidros & Esquadrias \\
\hline & Madeiras & Esquadrias, formas, forros e parte de estruturas \\
\hline & Isopor & Isolamento térmico \\
\hline & Gesso & Forros \\
\hline \multirow{3}{*}{ CLASSE C } & Massa Corrida & Acabamentos e regularizações de alvenaria \\
\hline & Impermeabilizante & Impermeabilização na área dos banheiros e cozinha \\
\hline & Lixas & Acabamentos e regularizações de alvenaria \\
\hline \multirow{3}{*}{ CLASSE D } & Tintas & \multirow{3}{*}{ Pintura } \\
\hline & Solventes & \\
\hline & Óleos & \\
\hline
\end{tabular}

Fonte: Autoria própria.

Segundo Ferreira et al. (2019), as propriedades e características químicas e físicas dos resíduos devem ser determinadas de maneira específica, por meio de ensaios apropriados, sendo extremamente importante a realização de estudos a fim de se melhorar a qualidade 
dos agregados reciclados e, ainda, promover a busca por novas tecnologias que visem sua adequação na produção de novos materiais. A partir dessas ações, é possível uma destinação adequada, com as devidas aplicações dos resíduos e um melhor aproveitamento das suas características.

Alguns parâmetros essenciais para a caracterização de materiais da Classe A são: composição gravimétrica, composição química e física, absorção de água, densidade do material aplicado em compósitos e as fases minerais presentes, pois as matérias-primas são variáveis de acordo com a jazida e sofrem influência do processo produtivo, dependendo de metodologias e técnicas utilizadas na fabricação de um determinado produto (SILVA, FUCALE, FERREIRA, 2019; LIMA, CABRAL, 2013).

Segundo Brasileiro e Matos (2015), as diferentes características afetam diretamente a qualidade do resíduo, sendo necessário realizar uma caracterização completa e analisar a composição do resíduo, para que se escolha adequadamente a qual processo de reaproveitamento o material será submetido. Além da caracterização, faz-se necessário um levantamento quanto à classificação e à quantificação de cada tipo de resíduo, pois a partir dos dados levantados é que serão encaminhados com mais precisão, seja para reciclagem, reutilização ou aterro.

O Quadro 3 apresenta a utilização de agregados reciclados que poderão ser aplicados a partir do material obtido com a triagem dos resíduos dos canteiros de obras.

Quadro 3: Utilização de Agregados Reciclados

\begin{tabular}{|c|c|c|}
\hline MATERIAL & CARACTERÍSTICAS* & UTILIZAÇÃO \\
\hline $\begin{array}{c}\text { Areia } \\
\text { Reciclada }\end{array}$ & $\begin{array}{c}\text { Material com dimensão máxima } \\
\text { inferior a 4,8mm. }\end{array}$ & $\begin{array}{c}\text { Argamassa de assentamento de alvenaria de } \\
\text { vedação, contrapisos, solo-cimento, blocos e } \\
\text { tijolos de vedação. }\end{array}$ \\
\hline Bica Corrida & $\begin{array}{c}\text { Material com dimensão máxima } \\
\text { de 63mm. }\end{array}$ & $\begin{array}{c}\text { Obras de base e sub-base de pavimentos, } \\
\text { reforço e subleitos de pavimentos, além de } \\
\text { regularização de vias não pavimentadas, aterros } \\
\text { e acertos topográficos de terrenos. }\end{array}$ \\
\hline $\begin{array}{c}\text { Brita } \\
\text { Reciclada }\end{array}$ & $\begin{array}{c}\text { Material com dimensão máxima } \\
\text { inferior a 39mm. }\end{array}$ & $\begin{array}{c}\text { Fabricação de concretos não estruturais e obras } \\
\text { de drenagens. }\end{array}$ \\
\hline $\begin{array}{c}\text { Pedrisco } \\
\text { Reciclado }\end{array}$ & $\begin{array}{c}\text { Material com dimensão máxima } \\
\text { de 6,3mm. }\end{array}$ & $\begin{array}{c}\text { Fabricação de artefatos de concreto, como } \\
\text { blocos de vedação, pisos intertravados, } \\
\text { manilhas de esgotos, dentre outros. }\end{array}$ \\
\hline Rachão & $\begin{array}{c}\text { Material com dimensão máxima } \\
\text { inferior a 150mm. }\end{array}$ & Obras de pavimentação, drenagens e \\
terraplenagens.
\end{tabular}

* Isentos de impurezas e proveniente da reciclagem de concreto e blocos cerâmicos.

Fonte: ABRECON (2016). 
A substituição de agregados convencionais por agregados reciclados deve ser feita com o devido cuidado e atenção no que se refere à qualidade dos resíduos que são a base para o material reciclado. Assim, salienta-se como imprescindível a realização de ensaios e estudos com o intuito de verificar a resistência mecânica, tanto do concreto como da argamassa (BASTOS, DA CRUZ, WOELFFEL, 2016).

Santana et al. (2011) destaca que o uso do agregado reciclado pode trazer benefícios à construção e, por ser um resíduo composto de materiais heterogêneos, alguns estudos e experimentos vêm sendo realizados com ênfase na aplicação desses resíduos em pavimentação ou como agregado em concreto para uso não estrutural.

O Sindicato da Indústria da Construção Civil aponta que a reciclagem de RCD tem um potencial econômico de negociação, em que o resíduo deixa de ser inutilizado e retorna ao mercado como agregado reciclado, possibilitando a geração de receita tanto no recebimento do resíduo quanto na venda dos agregados reciclados (SINDUSCON, 2015).

Apesar desse potencial de comércio, verificou-se que na região não há alternativas que facilitem a reutilização dos agregados, tendo em vista não existir na localidade nenhuma usina que execute o processo de trituração do RCD. Destaca-se como um fator limitante o escasso número de empresas que realizam a reciclagem nas proximidades das obras, além da insuficiência de pesquisas que analisem o potencial do material descartado.

Com esse cenário, vale destacar também que o Nordeste foi a região com menor índice de cobertura de coleta de resíduos urbanos no Brasil. Nessa região, foram geradas 53.975 toneladas em 2018, dentre as quais $81,1 \%$ foram coletadas e, destas, 6 em cada 10 toneladas foram destinadas a aterros controlados e a lixões, ou seja, mais de 28 mil toneladas por dia foram depositadas inadequadamente (ABRELPE, 2020).

Em comparação com os RCDs, o cenário não é diferente, uma vez que, em municípios de pequeno porte, como na região em estudo, não se verifica uma quantidade expressiva de associações, cooperativas ou empresas recicladoras. Consequentemente, os RCC precisam ser enviados para reciclagem em localidades distantes ou para a capital do estado, acarretando um custo de transporte e de logística que acaba refletido no valor da obra, porém, em se tratando da construção de casas populares, essa inserção se torna inviável.

Oliveira et al. (2012) afirma que alguns resíduos têm maiores possibilidades de serem reciclados, pois, além de tijolos e concreto submetidos à trituração e transformados em agregados para novas alvenarias, existe a possibilidade de aproveitamento da madeira, que 
pode ser novamente utilizada na construção, muitas vezes como calços ou painéis prensados. Além disso, materiais como o metal, o vidro e o plástico são passíveis de serem enviados a processos de reciclagem, o que ocorre comumente nas regiões onde existem empresas recicladoras.

Também tem sido pesquisada a combinação de RCD com materiais sintéticos alternativos, tais como borracha de pneus usados e polímeros de garrafas, que podem ser utilizados na substituição de materiais granulares naturais em sistemas drenantes. A presença de um geotêxtil envolvendo o material drenante alternativo pode servir como um elemento de filtro para o sistema (LIMA et al., 2019).

Pesquisadores e engenheiros apontam alguns elementos-chave para o sucesso do reuso e da reciclagem desses resíduos: a conscientização, a verificação de regulamentos e sistemas, as tecnologias de construção e a pesquisa e o desenvolvimento de gerenciamento (BLAISI, 2019).

De uma maneira geral, qualquer empreendimento da construção civil deve promover uma atitude positiva que abrace a sustentabilidade e as melhores práticas na aplicação de RCD em novos produtos ou processos. Por outro lado, consideram-se, entre os principais fatores que afetam o comportamento dos geradores de resíduos, as oportunidades existentes de reciclagem e a educação e o treinamento de funcionários.

A Resolução No 307 (CONAMA, 2002) foi estabelecida considerando a representatividade dos RCDs, bem como a viabilidade técnica e econômica de produção e uso de materiais provenientes de reutilização, reciclagem e beneficiamento desses resíduos. Pelo exposto, é relevante salientar que há dificuldades de reuso ou de reciclagem dos materiais gerados na obra pela falta de oportunidades facilitadoras desse processo, no qual a viabilidade técnica e econômica nem sempre é possível.

\subsection{Algumas alternativas para aproveitamento de RCD}

\section{Papel / Papelão}

Milhões de toneladas de papel são produzidos e usados em todo o mundo, principalmente em escritórios. A extração de celulose e o processo de produção de uma única folha de papel A4 a partir de matéria-prima celulósica é responsável por liberações de carbono no meio ambiente, chegando a $4,74 \mathrm{~g}$ de $\mathrm{CO}_{2}$ /folha (JOSHI et al., 2016). 
Na construção civil, os papéis são utilizados em sua grande maioria nos escritórios, como documentos, contratos e plantas, além das embalagens de produtos, como caixas de revestimentos e outros materiais. No canteiro de obras, os papéis e papelões devem ser armazenados de forma temporária de maneira adequada, em local seco e livre de umidade, e destinados a empresas ou organizações de catadores que reciclem esse material, com exceção daqueles que estejam contaminados.

Algumas empresas não reciclam as embalagens de cimento devido à grande presença das partículas de cimento que são contaminantes para o processo de reciclagem. Porém, as empresas que os utilizam na reciclagem afirmam que possuem boa qualidade como papelão reciclado para o revestimento de pilares circulares de concreto, em que, em sua composição, é acrescida uma película que impede que o concreto reaja com o papelão e não absorva água (RICCHINI, 2015).

\section{Plástico}

Para os plásticos recicláveis existe uma classificação a ser identificada no trabalho de triagem, conforme estabelece a norma da NBR 13.230 (ABNT, 2008) - Reciclabilidade e identificação de materiais plásticos. Os materiais poliméricos que não estejam contaminados devem ser separados de acordo com sua especificação, tais como: PET, EPS, PVC, poliestireno, poliamida, polietileno e polipropileno.

Tubos, conexões, juntas, forros de PVC que não podem ser reutilizados na obra podem ser reciclados. A reciclagem surge como a alternativa que mais se adequa no sentido de promover uma destinação correta desses materiais. Além disso, existem diferentes tipos de reciclagem dependendo da característica de cada um (RODRIGUES et al., 2017).

A American Society for Testing and Materials estabeleceu quatro tipos de reciclagem: a primária e a secundária são técnicas de reciclagem mecânica, pois incluem a reciclagem de polímeros por meio do aquecimento do material até uma certa temperatura e da alteração de sua forma física. A terciária (química, pirólise) e a quaternária (incineração) empregam critérios um pouco diferentes. Na pirólise, os subprodutos obtidos são de altos valores caloríficos, cujo processo consome alta energia. Na incineração de reciclagem quaternária com recuperação de calor, alguns plásticos como PVC devem ser removidos, pois gases nocivos são emitidos quando queimados no ambiente (SINGH et al., 2016).

Técnicas de aplicação dos polímeros em materiais para construção também surgem como alternativa, pois podem ser utilizados em blocos de concreto reforçado com fibra de 
polipropileno exposto a altas temperaturas (TANYILDIZI; ŞAHIN, 2017), na inserção de polímeros superabsorventes em mistura de materiais cimentícios (MECHTCHERINE et al., 2017), na adição de polímeros reforçados com fibra de vidro reciclada em concreto autoadensável (MASTALI et al., 2016) entre outras técnicas.

\section{$\underline{\text { Metal }}$}

É um material composto por metais ferrosos, geralmente resíduos de aço e ferro utilizados nas estruturas da construção que podem ser vendidos para recicladoras e até mesmo para siderúrgicas e indústrias de fundição.

Os metais são completamente reciclados e a reciclagem de uma tonelada de sucata de alumínio economiza cinco toneladas de bauxita, material natural não-renovável. Outro ponto positivo é que cada tonelada de aço reciclado gera uma economia de $1.140 \mathrm{~kg}$ de minério de ferro, $154 \mathrm{~kg}$ de carvão e $18 \mathrm{~kg}$ de cal. Referente ao alumínio, a energia pode ser economizada em cerca de $95 \%$ em relação ao processo primário, além de evitar que toda a lama vermelha (resíduo da mineração) seja gerada (RICCHINI, 2016).

Os aços utilizados na construção civil são do tipo aços longos, como vergalhões, perfis, arames, fio-máquina e pregos, e são produzidos em mini-mills ou aciarias elétricas (equipamentos em que o metal é fundido). Vinícius (2014) afirma que uma liga de carbono, quando aquecida, pode ser transformada em líquido e por essa fluidez pode ser reciclada de várias maneiras em telhas metálicas, sapatas ou pré-moldados.

Vale salientar que o uso das estruturas metálicas tem se tornado cada vez mais comum na construção, seja pelas usuais esquadrias, seja pelas estruturas formadas por perfis metálicos (VENTURA, 2009). Ressalta-se que, por serem peças e estruturas pré-fabricadas que geralmente são utilizadas em quantidades e tamanhos exatos, as perdas são mínimas (GOMES et al., 2018).

\section{$\underline{\text { Vidros }}$}

Segundo David (2016), o reaproveitamento do vidro pode ocorrer de duas formas: pela reciclagem ou pelo beneficiamento do material. Ele afirma que a indústria faz a reciclagem do seu material com o objetivo de transformar a matéria-prima pós-consumo em um novo produto, mas, quanto ao vidro quebrado, é possível fundi-lo novamente e assim produzir novas chapas ou embalagens. Esse resíduo geralmente é originado de esquadrias que às vezes não são recicladas, como no caso do vidro laminado, devido à inexistência de empresas 
de beneficiamento do material, as quais devem possuir usinas de separação do vidro com alumínio e plástico.

Os vidros, quando não misturados com outros materiais, são $100 \%$ recicláveis. Eles possuem boa resistência de compressão, tração, flexão e desgaste, pois sua maior composição base é sílica, tornando-se um material com grande viabilidade para constituir concretos e argamassa cimentícia (PAIVA, LIMA, 2019).

\section{$\underline{\text { Madeiras }}$}

As madeiras causam grande volume de resíduos, pois são utilizadas de diversas formas, como esquadrias, escoras, formas, entre outros. Algumas esquadrias podem ser reutilizadas se não estiverem expostas à influência direta da luz solar, de ventos, chuvas e se não tiverem sua deterioração adiantada.

Existe uma vasta possibilidade de reciclagem para a madeira, tais como: a utilização no processo de compostagem (RODRIGUES et al., 2016); a confecção de paletes (PLATINA; OLIVEIRA, 2018); o uso no design de superfície para revestimento (BRITO et al., 2016); a confecção de madeira plástica a partir de resíduos de madeira e poliolefínicos pós-consumo (MONSORES et al., 2019); na fabricação de compósito para isolamento térmico na construção (MOURA et al., 2020); na aplicação como resíduo estruturante no lodo de esgoto oriundo das Estações de Tratamento de Efluentes, usando reatores na escala de laboratório, sendo eficiente para biodegradabilidade do lodo de esgoto antes do processo de compostagem (SANTOS et al., 2019); e na produção de briquetes, produzidos a partir da serragem e outros resíduos oriundos do processo de beneficiamento de madeira, sendo um processo de reconstrução de material particulado por meio da aplicação de temperatura e pressão e na compactação de resíduos, em que a elasticidade natural das fibras é destruída (DONATO \& TAKENAKA, et al., 2016). A briquetagem acarreta um material com pequeno volume, alta densidade e com alto poder calorífico (FURTADO et al., 2010).

\section{Gesso}

De acordo com Pinheiro (2011), o uso do gesso na construção civil aumentou significativamente nos últimos anos, com um crescimento de cerca de $20 \%$ a cada ano, e sua utilização pode ocorrer de diversas formas: molduras, forros, rebaixamento de tetos, componentes de placas de reboco, entre outros. Esse crescimento gerou uma grande 
preocupação, pois se descartado de maneira indevida, o gesso pode contaminar o solo e os lençóis freáticos, podendo emitir gás sulfúrico, que é altamente tóxico e inflamável.

A Resolução No 431 (CONAMA, 2011) alterou a classificação do gesso, passando-o para classe B, o que minimiza o impacto causado por esse material. A reciclagem do gesso pode ocorrer de duas formas: quando o material é submetido ao processo de moagem, podendo ser usado como fertilizante para o setor da agricultura, em que sua atuação se dá como um corretivo da acidez do solo e melhoramento de suas características (NOGUEIRA et al., 2016); pode também ser utilizado na indústria do cimento como um ingrediente que atua como retardante da cura do cimento (GONÇALVES et al., 2020); ou retornar ao processo construtivo se, após a moagem, for submetido à calcinação, transformando-o em gesso reciclado e apto para retornar ao início da cadeia produtiva (CIPRIANO DA SILVA et al., 2018).

\section{$\underline{\text { Isopor }}$}

O Poliestireno Expandido - EPS ou isopor, como é conhecido, é comumente utilizado na construção de pequeno porte em forros ou painéis (BORGES et al., 2017).

A reciclagem desse material é bastante viável, podendo ocorrer em blocos de concreto, com substituição parcial do agregado graúdo por poliestireno expandido reciclado (GONÇALVES e VASCONCELOS, 2019) para a produção de concreto leve. Este, além de ter uma alta versatilidade, é também vantajoso quanto à densidade aparente, à porosidade $\mathrm{e}$ ao módulo de elasticidade (STRECKER, SILVA, PANZERA, 2014).

\section{Solos}

Os solos são, em sua maioria, provenientes de cortes do terreno, podendo esse volume variar quanto ao corte e ao aterramento. Para seu uso é necessário, portanto, verificar a adequabilidade do solo, o tipo de solo, suas características e resistências, o uso e a finalidade a serem empregados (CAPOBIANCO et al., 2017). Também, para melhorar suas propriedades de resistência, pode ser utilizado a partir da mistura com outros resíduos cerâmicos da construção (AL-BARED et al., 2018).

\section{Componentes cerâmicos e cimentícios}

$\mathrm{Na}$ construção civil os componentes cerâmicos são oriundos de telhas, blocos, pastilhas de revestimento e pisos; enquanto os componentes cimentícios provêm das 
argamassas, concretos e blocos de alvenaria. Segundo Morand (2016) os componentes cerâmicos e cimentícios devem ser britados e reaproveitados como agregados, podendo ser utilizados como aditivo pozolânico.

De uma forma geral, esses materiais podem ser transformados em resíduo reciclado e serem utilizados em: pavimentação como bases e sub-bases, reforço de leito e subleito, regularização de vias não pavimentadas, como agregados para construção, aterros, acerto topográfico de terrenos, blocos de concreto, argamassas de assentamento de alvenaria de vedação, contrapisos, solo-cimento, blocos e tijolos de vedação, entre outros. Ressalta-se, no entanto, que a substituição dos agregados reciclados não deve ser completa, e sim parcial, a fim de se conservar as resistências necessárias para as distintas e variadas finalidades descritas acima (BRAGAGNOLO; KORF, 2020).

\subsection{Desafios no gerenciamento de Resíduos de Construção e Demolição (RCD) em construção de pequeno porte}

O processo de reintrodução de um resíduo como parte da construção civil deve ser analisado de maneira minuciosa, avaliando-se toda alternativa de reciclagem para os diversos materiais com o intuito de escolher a melhor opção. Variáveis como o tipo de resíduo, a tecnologia empregada e a utilização proposta para o material reciclado podem tornar o processo de reciclagem ainda mais impactante do que o próprio resíduo.

Para que haja o desenvolvimento de algumas ações e práticas sustentáveis, é necessário avaliar todo o ciclo de vida do empreendimento, desde sua concepção, o projeto, as etapas do processo construtivo, até a manutenção e a demolição, analisando os aspectos econômico, social e ambiental.

Destaca-se, nesse contexto, a relevância do estudo para redução dos impactos negativos e o cumprimento de estratégias tecnológicas e gerenciais para implantação de canteiros de obras mais sustentáveis. Uma construção sustentável não prioriza a solução perfeita, mas um equilíbrio entre a viabilidade econômica, as limitações do empreendimento e o contexto social.

Apesar dos inúmeros benefícios que o reaproveitamento de maneira geral pode trazer, tanto aos empreendedores como ao meio ambiente, há algumas dificuldades para que tais benefícios façam parte dos projetos de novas edificações, seja por falta de conhecimento sobre o tema ou pela simples falta de interesse. Ainda existe uma parcela grande de pequenos 
construtores que gerenciam os resíduos como produtos de total descarte e não consideram que a reutilização e a reciclagem podem acrescentar ganhos nas obras e afetar de maneira positiva o meio ambiente.

Os subprodutos da reciclagem, como os agregados reciclados, podem ser utilizados em várias áreas. No entanto, não se deve analisar apenas o aspecto financeiro e os benefícios ambientais, mas também verificar os aspectos relativos à segurança, avaliando a resistência dos materiais, a fim de que estes venham atender às solicitações e aos esforços a que serão submetidos. Nesse sentido, torna-se relevante verificar a eficiência técnica do produto fabricado, comparando o convencional ao material reciclado.

Pham e Kim (2019) revelaram que práticas ambientais, econômicas e sociais têm influências positivas no desenvolvimento da sustentabilidade e que as competências de liderança fortalecem a relação práticas ambientais versus sustentabilidade. No entanto, a indústria da construção precisa de mais esforços para melhorar os aspectos relativos à sustentabilidade e à atração dos grupos de profissionais. Para isso, as práticas sustentáveis precisam ser mais relevantes e necessárias tanto para as empresas, quanto para os profissionais, bem como os incentivos econômicos e a força de trabalho que resultem na implementação de iniciativas sustentáveis, desenvolvimento econômico sustentável e uso eficiente de recursos.

Enfatiza-se que, comumente, as obras de pequeno porte são executadas sem planejamento ambiental prévio e não manejam adequadamente os resíduos gerados no canteiro durante a fase de execução da obra. Consequentemente, não se adotam medidas que visem a redução dos resíduos até a entrega da edificação ao cliente.

Cortês et al. (2012) destaca algumas práticas que representam o compromisso com a sustentabilidade no canteiro de obra: elaborar eventos envolvendo temas sobre a responsabilidade ambiental; criar manual de licenciamento ambiental e identificação de riscos de responsabilidades; adaptar gradativamente as instalações da empresa, bem como canteiros de obras e projetos, aos conceitos atuais de preservação ambiental; incentivar e dar suporte aos funcionários que desejem se organizar em grupos para atuação voluntária em instituições e obras sociais e ambientais; desenvolver projetos educativos e profissionalizantes para as comunidades próximas aos empreendimentos; além de estabelecer a formação de parcerias, consórcios ou terceirização de serviços.

Nos empreendimentos analisados, constatou-se que os gestores responsáveis pelas construções residenciais não priorizam ações com vista a reduzir a geração de resíduos ao 
longo do ciclo de vida de seus empreendimentos. Assim, percebe-se que a ausência no cumprimento de políticas públicas locais e a preocupação constante em reduzir os custos de produção são os principais desafios enfrentados pelos gestores.

Nesse sentido é de suma importância que a prática de empreendimentos que utilizam materiais reciclados em seus processos construtivos se propague, considerando que a existência de materiais de construção civil recicláveis no mercado tende a viabilizar que novas construções se adequem a esse processo.

A reutilização de resíduos em obras de pequeno porte merece também um destaque quanto aos aspectos econômicos, pois o caminho para atingir um índice satisfatório de reaproveitamento ainda é longo e está ligado diretamente à reciclagem, cuja viabilidade ainda possui lacunas no que se refere a pesquisas, que precisam ser preenchidas com estudos e experimentos.

\section{CONCLUSÃO}

Apesar de ainda ser preciso transpor muitos obstáculos para que a reciclagem de resíduos da construção civil seja uma realidade nos canteiros de obra de todo o país, é necessário ressaltar que as iniciativas em benefício do meio ambiente no ramo da engenharia vêm se tornando cada vez mais recorrentes.

A falta de projetos complementares tem comprometido a compatibilização e a racionalização do reaproveitamento dos resíduos pelo próprio setor da construção civil. Os custos durante a execução da obra são a parte mais desafiadora, portanto, as especificações de reciclagem e de reuso que foram sugeridas são as mais simples possíveis, com a finalidade de que essas ações não causem ônus adicional à execução da obra.

Aliado ao reaproveitamento dos resíduos está a ciência, que, por meio de estudos e pesquisas, torna possível buscar novas tecnologias de reciclagem inserindo novos produtos ou subprodutos de forma satisfatória na cadeia construtiva.

Ademais, é válido que seja realizado um levantamento sobre a análise financeira de reutilização e reciclagem dos resíduos sólidos da construção civil, bem como a viabilidade da criação de um sistema de dados como uma rede de informações integradas sobre a quantidade e tipo de resíduo gerado por obra, locais de encaminhamento, usinas recicladoras próximas à região da obra e/ou outras obras que tenham interesse no reuso de alguns 
materiais, de maneira que esses dados incentivem e facilitem a reutilização e a reciclagem dos Resíduos de Construção e Demolição.

\section{REFERÊNCIAS}

Al-BARED, M. A. M.; MARTO, A.; LATIFI, N. Utilization of Recycled Tiles and Tyres in Stabilization of Soils and Production of Construction Materials - A State-of-the-Art Review. KSCE J Civ Eng, 22, 2018. Disp. em: https://doi.org/10.1007/s12205-018-1532-2. Acesso em: 14 jul 2018.

ASSOCIAÇÃO BRASILEIRA PARA RECICLAGEM DE RESÍDUOS DA CONSTRUÇÃO CIVIL E DEMOLIÇÃO - ABRECON. Reciclagem de entulho Mercado. São Paulo, 2016. Disponível em: https://abrecon.org.br/entulho/mercado/. Acesso em: 14 jul 2018.

ASSOCIAÇÃO BRASILEIRA DE EMPRESAS DE LIMPEZA PÚBLICA E RESÍDUOS ESPECIAIS - ABRELPE. Panorama dos Resíduos Sólidos no Brasil 2018/2019. São Paulo, 2020.

ASSOCIAÇÃO BRASILEIRA DE NORMAS TÉCNICAS - ABNT. Norma Brasileira No 13.230 de 17 de dezembro de 2008. Embalagens e acondicionamento plásticos recicláveis - Identificação e simbologia, 2008.

BAMGBADE, J. A.; KAMARUDDEEN, A. M.; NAWI, M. N. M.; ADELEKE, A. Q.; SALIMON, Maruf Gbadebo; AJIBIKE, W. A. Analysis of some factors driving ecological sustainability in construction firms. Journal of Cleaner Production, 208, p. 1537-1545, 2019.

BASTOS, Isadora Andrade; DA CRUZ, Leandro Faria; WOELFFEL, Anderson Buss. Fabricação de blocos de concreto para vedação com o uso de agregados reciclados em canteiro de obras. Revista Científica Faesa, Vitória, ES, v. 12, n. 1, p. 52-58, 2016.

BLAISI, Nawaf I. Construction and demolition waste management in Saudi Arabia: Current practice and roadmap for sustainable management. Journal of Cleaner Production 221, p. 167-175, 2019).

BORGES, Éverton; GONÇALVES JUNIOR, Elcio Luiz; ALMEIDA, Indira Maira Fernandes. Isopedra, suas características físicas ante ao EPS - Poliestireno Expandido. Revista Científica de Ciências Aplicadas da FAIP, v. 4, n. 7, mar. 2017.

BRAGAGNOLO, Lucimara; KORF, Eduardo Pavan. Aplicação de resíduos na fabricação de concreto: como técnicas analíticas de caracterização podem auxiliar na escolha preliminar do material mais adequado? Revista Matéria, Artigos e-12560, 2020.

BRASILEIRO, L. L.; MATOS, J. M. E. Revisão bibliográfica: reutilização de resíduos da construção e demolição na indústria da construção civil. Revista Cerâmica, 61, p. 178-189, 
2015. Disponível em: http://dx.doi.org/10.1590/0366-69132015613581860. Acesso em: 14/07/2018.

BRITO, Bruna Ramires; FORCATO, Marcelo dos Santos; MOURA, Monica Cristina. Reutilização da Madeira Temporária da Construção Civil em Produto de Superfícies. Blucher Design Proceedings, vol. 9, n. 2, outubro de 2016.

CAPOBIANCO, Oriana; COSTA, Giulia; BACIOCCHI, Renato. Assessment of the Environmental Sustainability of a Treatment Aimed at Soil Reuse in a Brownfield Regeneration Context. Journal of Industrial Ecology, vol. 22, n. 5., p. 1027-1038, outubro de 2018.

CORTÊS, R. G.; FRANÇA, S. L. B.; QUELHAS, O. L. G.; MOREIRA, M. M.; MEIRINO, M. J. Contribuições para a Sustentabilidade na Construção Civil. Sistemas \& Gestão, 6 (3), p. 384-397, 2012. Disp. em: https://doi.org/10.7177/sg.2011.V6.N3.A10. Acesso em: 14 jun 2018.

DAVID, Stefan Jacques. Vidro pode ser reciclado infinitamente. Revista Digital AECWeb, 2016. Disp. em: https://www.aecweb.com.br/revista/materias/vidro-pode-serreciclado-infinitamente/9457. Acesso em 13 jun 2017.

DONATO, Cláudio José \& TATAKENAKA, Edilene Mayumi Murashi. O Aproveitamento de Resíduos de Madeira para o Desenvolvimento Sustentável. Periódico eletrônico Fórum Ambiental da Alta Paulista, vol. 12, n. 4, 2016.

CIPRIANO DA SILVA, Deborah Grasielly; SANTANA, Clóvis Veloso de; PÓVOAS, Yeda Vieira. Production of components with plaster residue and sodium citrate: physical, mechanical, rheological analysis. Ambiente Construído, Porto Alegre, v. 19, n. 2, p. 33-43, abr./jun. 2019.

CONSELHO NACIONAL DO MEIO AMBIENTE - CONAMA. Resolução No 275 de 25 de abril de 2001. Estabelece o código de cores para os diferentes tipos de resíduos, a ser adotado na identificação de coletores e transportadores, bem como nas campanhas informativas para a coleta seletiva. 2001 .

CONSELHO NACIONAL DO MEIO AMBIENTE - CONAMA. Resolução No 307 de 05 de julho de 2002. Estabelece diretrizes, critérios e procedimentos para a gestão dos resíduos da construção civil. 2002.

CONSELHO NACIONAL DO MEIO AMBIENTE - CONAMA. Resolução No 431 de 24 de maio de 2011. Altera o art. $3^{\circ}$ da Resolução $N^{\circ} 307 / 2002$, estabelecendo nova classificação para o gesso.

CONSELHO NACIONAL DO MEIO AMBIENTE - CONAMA. Resolução No 448 de 18 de janeiro de 2012. Altera os arts. $2^{\circ}, 4^{\circ}, 5^{\circ}, 6^{\circ}, 8^{\circ}, 9^{\circ}, 10$ e 11 da Resolução $N^{\circ} 307 / 2002$.

FERNANDES, Maria da Paz Medeiros; SILVA FILHO, Luiz Carlos Pinto da. Um modelo orientativo para a gestão municipal dos RCCs. Revista Ambiente Construído, Porto Alegre, v. 17, n. 2, p. 21-38, abr./jun. 2017. 
FERREIRA, R. L. S.; ANJOS, M. A. S.; PEREIRA, J. E. S.; FONSECA, N. J. M.; NÓBREGA, A. K. C. Avaliação das propriedades físicas, químicas e mineralógicas da fração fina (<150 mm) do agregado reciclado de RCD. Revista Cerâmica, ed. 65, p. 139146, 2019. Disp. em: http://dx.doi.org/10.1590/0366-69132019653732453.2019. Acesso em: 14 jun 2018.

FURTADO, Thielly; VALIN, Marina; BRAND, Martha; FRANCISCO, Antonio; BELLOTE, Jurado. Variáveis do processo de briquetagem e qualidade de briquetes de biomassa florestal. Revista Pesquisa Florestal Brasileira, vol. 30, 2010.

GOMES, Brunna Frias; ODAGUIRI, Gustavo Okabayashi; OLIVEIRA, Valmir Torres de. Estudo da Utilização de Estruturas Metálicas na Construção Civil. Rev. Episteme Transversalis, Volta Redonda-RJ, v. 9, n. 1, p. 83-101, jan./jun. 2018.

GONÇALVES, Elaine Cristina Zuquetti; AMORIM, Esther Ferreira de; ALVES, Isabela Alda; BORGES, Jéssica Lorrany Fernandes de; FRAZÃO, Laura Rodrigues Bernardes; RESENDE, Maressa Guimarães; PEREIRA, Rafaella Cristina; NAHIME, Bacus de Oliveira. Aditivos e Adições no Concreto. Global Science and Technology, Rio Verde, v. 13, n. 01, p. 88-102, jan/abr. 2020.

GONÇALVES, Paulo; VASCONCELOS, Raimundo. Avaliação térmica, física e mecânica de blocos de concreto com poliestireno expandido reciclado. Ambiente Construído, vol. 19, n. 4. 2019.

JACOBI, Pedro Roberto; BESEN, Gina Rizpah. Gestão de resíduos sólidos em São Paulo: desafios da sustentabilidade. Revista Estudos avançados, ed. 25, p. 135-158, 2011.

JOSHI, Gyanesh; NAITHANI, Sanjay; VARSHNEY, V.K.; BISHT, Surendra S.; RANA, Vikas. Potential use of waste paper for the synthesis of cyanoethyl cellulose: A cleaner production approach towards sustainable environment management. Journal of Cleaner Production, vol. 142, 4, p. 3759-3768, 2017.

KLEIN, Flávio Bordino; GONÇALVES-DIAS,Sylmara Lopes Francelino. A deposição irregular de resíduos da construção civil no município de São Paulo: um estudo a partir dos instrumentos de políticas públicas ambientais. Revista Desenvolvimento e Meio Ambiente, vol. 40, p. 483-506, 2017.

LIMA, Augusto Junior Silva; MARTINS, Gustavo Mota; ALMEIDA, Juliana Flávia Pedras; NASCIMENTO, Kelvin Alex Cardoso; OLIVEIRA, Sérgio Magos de; VALENTIM, Thiago Cirilo; MELO, Daniela Duarte Ventura; REIS, Erlano Campos dos. Reutilizaçãa de Resíduos de Construção e Demolição (RCD) a fim de reduzir a extração de recursos minerais. Revista Expressão, n. 1, 2019.

LIMA, Adriana Sampaio; CABRAL, Antonio Eduardo Bezerra. Caracterização e classificação dos resíduos de construção civil da cidade de Fortaleza (CE). Revista Eng. Sanitária e Ambiental, v. 18, n. 2, p. 169-17, 2013.

MASTALI, M.; DALVAND, A.; SATTARIFARD, A.R. The impact resistance and mechanical properties of reinforced self-compacting concrete with recycled glass fibre reinforced polymers. Journal of Cleaner Production, vol. 124, 15, p. 312-324, 2016. 
MECHTCHERINE, V.; SCHRÖFL, C.; WYRZYKOWSKI, M. et al. Effect of superabsorbent polymers (SAP) on the freeze-thaw resistance of concrete: results of a RILEM interlaboratory study. Mater Struct, 50, 14, 2017.

MONSORES, Karollyne Gomes Castro; MONTEIRO, João Raphael; RACCA, Jonatas; CARDOZO, Stephane; PORTAL, Luciana. Obtenção e Caracterização de Madeira Plástica a Partir de Resíduos Pós-Consumo. Revista Iberoamericana de Polímeros y Materiales, vol. 20 (3), maio de 2019.

MORAND, Fernanda Guerra. Estudo das principais aplicações dos resíduos de obra como materiais de construção. Projeto de graduação em engenharia civil, Escola Politécnica da Universidade Federal do Rio de Janeiro, Rio de Janeiro, 2016.

MOURA, Ingrid Rebouças de; SILVA, Geovanne Lopes Cruz da; ALMEIDA, José Carlos Gomes de; COSTA, Emerson Bruno da; SOUZA, Wendell Rossine Medeiros de; VIANA, Herbert Ricardo Garcia. Reutilização de Resíduos de Serraria como matéria prima para Fabricação de Material Compósito de Isolação Térmica. Revista Iberoamericana de Polímeros y Materiales, vol. 21(2), março de 2020.

NOGUEIRA, Kenio Batista; ROQUE, Cassiano Garcia; BORGES, Mônica Cristina Rezende Zuffo; TROLEIS, Maria Júlia Betiolo; BARRETO, Rafael Ferreira; OLIVEIRA, Marcela Pacola. Atributos físicos do solo e matéria orgânica sob dois manejos e efeito residual da aplicação de calcário e gesso agrícola. Revista de la Facultad de Agronomía, La Plata, vol. 115 (1), p. 45-54, 2016.

OLIVEIRA, Maria Cleide Ribeiro de; SILVA, Allyson Leandro Bezerra da; PEREIRA, Francisco Flaviano A.; COSTA, Gabriel Louiz Silva da; MARQUES, Samuel Apolinário. Argamassa produzida com resíduo de vidro substituindo o agregado miúdo. Congresso Norte Nordeste de Pesquisa e Inovação - CONNEPI, Palmas/TO, 2012.

PAIVA, Camila Cunha; LIMA, Leyliane Oliveira de. Avaliação do comportamento mecânico do concreto com a substituição do agregado miúdo por vidro. Revista Eletrônica da Reunião Anual de Ciência-e-RAC, v. 9, n. 1, 2019.

PHAM, Hai; KIM, Soo-Yong. The effects of sustainable practices and managers' leadership competences on sustainability performance of construction firms. Sustainable Production and Consumption, v. 20, p. 1-14, 2019.

PINHEIRO, Sayonara Maria de Moraes. Gesso reciclado: avaliação de propriedades para uso em componentes. Tese de doutorado, Universidade Estadual de Campinas, São Paulo SP, 2011.

PLATINA, I. D.; OLIVEIRA, A. L. Reutilização dos Resíduos de Madeira da Confecção de Paletes. Interface Tecnológica, [S. 1.], v. 15, n. 2, p. 232-244, 2018.

Ricardo. Reciclagem de sacos de cimento. São Paulo, 2015. Disponível em: http://www.setorreciclagem.com.br/reciclagem-de-papel/reciclagem-de-sacos-de-cimento/. Acesso em: 12 jun 2017. 
RICCHINI, Ricardo. Reciclagem de metal. São Paulo, 2016. Disponível em: http://www.setorreciclagem.com.br/reciclagem-de-metal/reciclagem-de-metal/. Acesso em: 12 jun 2017.

RODRIGUES, Ana C. da Silva; MOREIRA, Jefferson F. Mendes; SOUZA FILHO, Luiz Brito de; NUNES, Valéria D. Barros. Vias de reciclagem dos polímeros polipropileno (PP) e poliestireno (PS): um estudo bibliográfico. Revista Iberoamericana de Polímeros, vol. 18, n. 3, p. 145-160, 2017.

RODRIGUES, Paula Raquel Barreto; PICANÇO, Aurélio Pessôa; SERRA, Juan Carlos Valdés; GUARDA, Emerson Adriano; LIMA JUNIOR, Amitai Silva. Estudo do Potencial de Reutilização dos Resíduos de Poda do Município de Palmas - TO. Revista Engenharia Ambiental - Espírito Santo do Pinhal, v. 13, n. 1, p. 144-154, jan/jun, 2016.

ROQUE, Rodrigo Alexander Lombardi; PIERRI, Alexandre Coan. Uso inteligente de recursos naturais e sustentabilidade na construção civil. Research, Society and Development, 8 (2), 2019. Disp. em: http://dx.doi.org/10.33448/rsd-v8i2.703. Acesso em 01 fev 2019.

SANTANA, Valquiria Melo de; PAES, Filipe Pereira; SANTANA, Diego da Silva; CERQUEIRA, Milena Borges dos Santos; SILVA, Francisco Gabriel Santos; ARAGÃO, Hélio Guimarães. Utilização de concreto reciclado na aplicação de elementos estruturais. XV Encontro Latino Americano de Iniciação Científica e XI Encontro Latino Americano de Pós Graduação, ed. XV. São José dos Campos: Universidade do Vale do Paraíba, 2011.

SANTOS, Débora Evelyn Christo dos; MAEDA, Shizuo; SOARES, Márcia Toffani Simão. Aplicação de materiais alcalinos para a higienização da mistura lodo celulósico e cinzas de madeira. Comunicado técnico No 430. Embrapa. Colombo, PR. Agosto, 2019.

SILVA, Aline Cátia da; FUCALE, Stela; FERREIRA, Silvio Romero de Melo. Efeito da adição de resíduos da construção e demolição (RCD) nas propriedades hidromecânicas de um solo areno-argiloso. Revista Matéria (Rio de Janeiro). vol. 24, n. 2, e12355. Disp. em: https://doi.org/10.1590/s1517-707620190002.0670.

SINDUSCON. Gestão ambiental de resíduos da construção civil-avanços institucionais e melhorias técnicas. São Paulo, 2015.

SINGH, Rupinder; SINGH, Narinder; FABBROCINO, Francesco; FRATERNALI, Fernando; AHUJA, I.P.S. Waste management by recycling of polymers with reinforcement of metal powder. Composites Part B: Engineering, vol. 105, 15, p. 23-29, 2016.

STRECKER, K.; SILVA, C. A.; PANZERA, T. H. Fabricação e caracterização de compósitos a base de cimento com incorporação de poliestireno expandido (isopor). Revista Cerâmica, ed. 60, p. 310-315, 2014.

TANYILDIZI, Harun; ŞAHIN, Murat. Taguchi optimization approach for the polypropylene fiber reinforced concrete strengthening with polymer after high temperature. Structural and Multidisciplinary Optimization, 55, p. 529-534, 2017. 
VENTURA, Ana Mafalda F.M. Os compósitos e a sua aplicação na reabilitação de estruturas metálicas. Ciência \& Tecnologia dos Materiais, v. 21 n. 3-4, p. 10 19, Lisboa, 2009.

VINÍCIUS, Bruno. Reciclagem de resíduos da construção civil. São Paulo, 2014. Disp. em: http://eugestor.com/editoriais/2014/05/reciclagem-de-residuos-da-construcao-civil/. Acesso em: 12 jun 2017. 